\title{
A review of tangential composite and radial composite gear inspection
}

\author{
M. Pueo ${ }^{*}$, J. Santolaria ${ }^{2}$, R. Acero ${ }^{1}$, A. Gracia $^{1}$ \\ ${ }^{1}$ Centro Universitario de la Defensa. Academia General Militar. Ctra. Huesca s/n. 50090, Zaragoza, Spain \\ ${ }^{2}$ Department of Design and Manufacturing Engineering, University of Zaragoza. María de Luna 3, 50018 Zaragoza, Spain \\ * Corresponding author. Tel. +34 976739836, fax +34 976739824, E-mail: mpueo@unizar.es
}

KEYWORDS: Gear metrology, Transmission error, Tangential composite inspection, Radial composite inspection, Single-flank rolling test, Double-flank rolling test

\begin{abstract}
This paper presents an overview of the literature on tangential composite and radial composite gear inspection. It demonstrates - by dealing with their origins and key milestones in their history and development - the important role that inspections play in terms of the functional nature of the gears concerned. This comprehensive consideration of the subject also attempts to demonstrate how the lack of clear guidelines and standards designed to unify the criteria applied to testing, the interpretation of results and calibration of equipment, along with the number of simultaneous variables involved in trials of this type, leads to doubts (including with respect to the actual standards concerned) as to whether these tests are valid, or instead accepted only has partial validations. Even so, the repeatability of the experimental data demonstrates not only their metrological potential, with respect to functionality, but also the fact that they are both effective and original.
\end{abstract}

\section{Introduction}

Mechanisms containing gears have existed for several thousand years. Despite their development from the Industrial Revolution onwards, and after the appearance of the machine tool, it was not until the first decade of the $20^{\text {th }}$ century, with its need for higher transmission speeds, that the emergence of the gear-cutting machine made it possible to improve considerably the quality of the tooth surfaces. As with the other production processes involved, this improvement in precision was associated with the evolution of control and monitoring systems. From the 1920s onwards, with the invention of a gear inspection machine based on the method of examining the involute tooth profile relative to the base circle, the inspection of gears began to be more reliable, thanks to the simplicity of the procedure. This can be considered as the starting point of current gear metrology. Various items of equipment have been developed since then, adapted to new designs and the needs of high-speed transmissions [1], [2].

The inspection of gears is a wide-ranging and complicated affair, due to the large variety of types, sizes, configurations and different parameters [3] involved. There is for this reason a virtually infinite number of both manual and automatic measuring techniques; ranging from workshop-bench procedures to complex, analytical evaluation carried out in metrological laboratories. Partial verifications must also be performed throughout the production process in order to guarantee the required precision. Inspections can help to identify not only the quality of the gears, but also the correctness of their machining and the condition of the cutting tools used [4]. When it comes to performing this task, rolling tests are a good alternative way of carrying out a fast but thorough inspection, thereby allowing us both to verify the production conditions of a set of transmission gears and predict its future behaviour.

This paper gives a general description of the rolling tests concerned, while explaining their functioning principles, the parameters that they verify and the interpretation of the results; before going on to give a summary of the origins and key milestones in the history of such rolling gear tests. Attention is also paid to 
current tendencies associated with various research groups, which have created great interest; along with the possibilities offered by new inspection techniques in the growing area of microfabrication. It also includes a summary of the corresponding standards, and their evolution up to the current way in which they are applied to single-flank or double-flank rolling tests.

\section{The metrology of gears}

Metrology, as applied to gears, can be divided into two classes; differentiated by the type of information that each one provides. Analytical measurement attempts, on one hand, to quantify readings obtained during production, and verify whether they conform to the geometric data of the original design. Functional checks, on the other hand, focus on guaranteeing that a gear will work correctly, regardless of its margins of tolerance, as these can sometimes be accumulated or compensated for by its conjugate gear. The former therefore generally tend to be more quantitative, while the latter are more qualitative [5], [6].

\subsection{Analytical measurements}

A wide variety of possibilities exists within the available range of individual, direct, geometric methods of measurement. These run from traditional, manual methods that verify the main dimensions of the teeth, to powerful coordinate-measuring machines (CMMs) with adapted operating cycles, and dedicated, high-precision gear-measuring instruments (GMIs) [7].

Checks carried out with simple manual instruments such as micrometers, callipers and dial indicators, together with pins and balls, are both fast and cost-effective (Figure 1). It is for these reasons that they are widely used for initial inspection purposes, and to ensure that the various production stages are not subject to any ongoing defects [4]. They can be employed to measure individual tooth thickness, the chordal thickness of a series of teeth, the gap between teeth (to determine the amount of backlash), the reference diameter and even the eccentricity of the teeth.
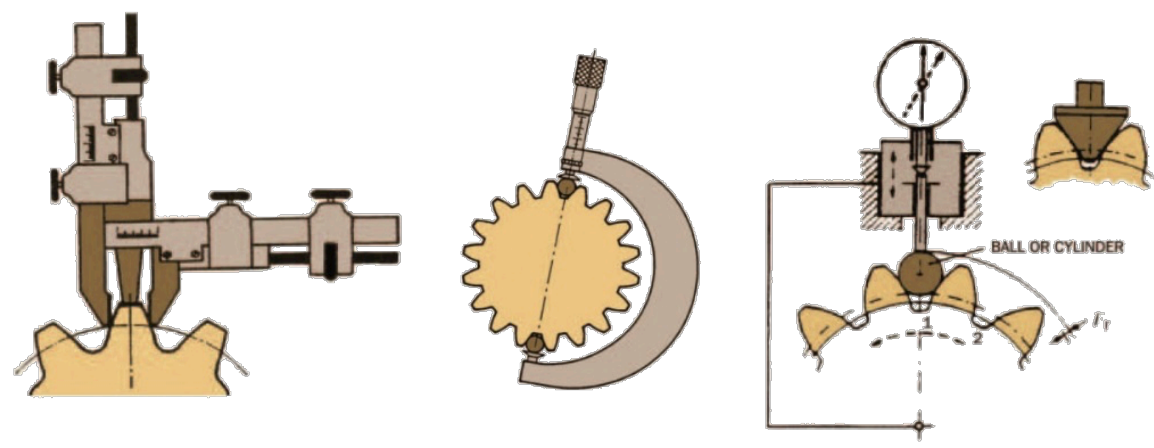

Figure 1. Examples of manual inspection tools (source: [4])

If quality control of the final manufacturing process is to be thorough, the use of automatic inspection techniques based on continuous detection is recommendable. These take multiple readings from along a given trajectory, and then compare them to the theoretical model established in the corresponding standards (Figure 2). The monitoring of a gear's typical parameters, such as deviation of its tooth profile, tooth distortion, pitch deviation, runout or tooth thickness, along with the detection of other shape-related tolerances, dimensions and positions, can be carried out by loading the workpiece into the machine and aligning it only once. This helps to provide more-accurate measurement readings, while allowing possible errors to be analysed either separately or in terms 
of mutual association, and furthermore reducing the time required to carry out a full inspection of the gears concerned [7].
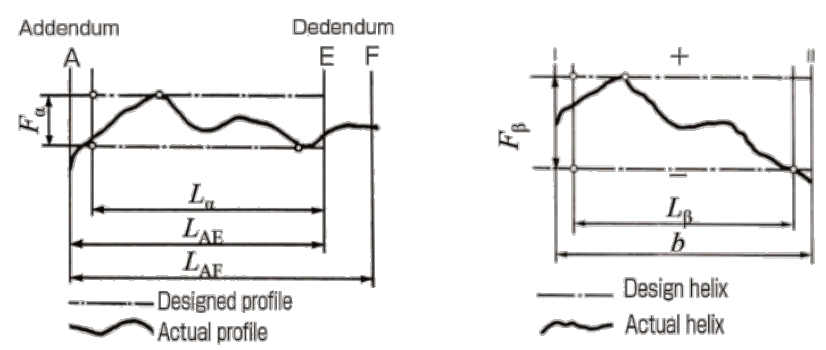

Figure 2. $\quad$ Example of profile deviation and helix deviation (source: [4])

GMIs, which are either CNC- (Computer Numerical Control) or PC-controlled, carry out continuous-detection measurement cycles based on the geometry of the gear being measured (Figure 3 ). These operating cycles can be used to inspect complete sets of gears, and also the cutting tools employed in their production. Machines of this type, which are referred to as "dedicated", can monitor the geometry of cylindrical, spur and helical gears, hob cutters and other cutting tools, shavers, worm and worm gears, bevel gears and hypoid gears, along with revolving geometric items in general, on the basis of user-defined cycles.
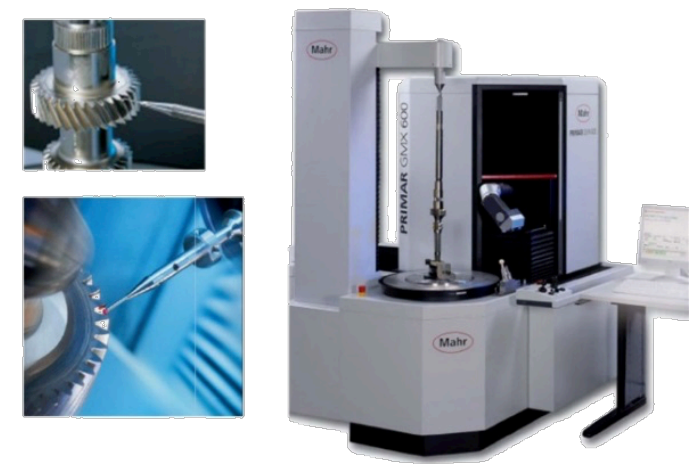

Figure 3. GMI gear-measuring instrument (source: Mahr)

Traditional-type CMMs, on the other hand, can be equipped with a bench-mounted rotary table in order to avoid the use of complex multiple probing styluses. The gear-measuring cycles are incorporated into the software for this purpose (Figure 4). Although the main factor limiting the use of CMMs for the measurement of gears has always been their lack of versatility when it comes to the positioning of the heads, the past decade has seen the development of specific, more-flexible systems designed for fitting to CMMs, which use coordinates to measure the gears concerned. They currently work on the basis of rotary axes, and are even able to move along predefined traverses, which can help in the measurement of gears with complex geometry, while also reducing the time required to carry out the operation [7], [8]. 


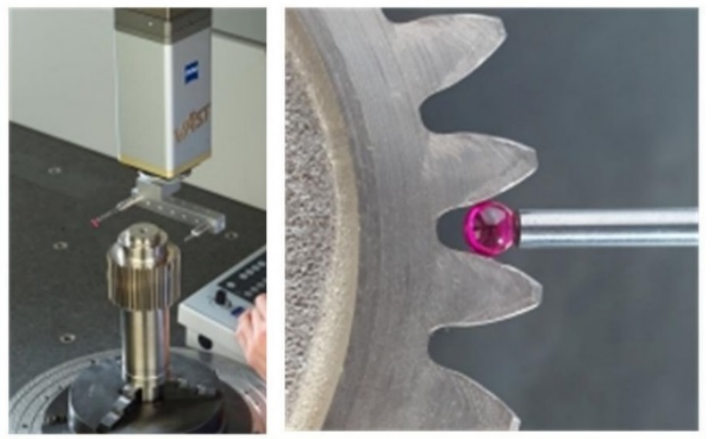

Figure 4. Gear measurement by means of CMM (source: Zeiss)

The metrological performance and versatility of GMIs still outpace CMMs in terms of both precision and productivity, and few manufacturers of gears therefore use CMMs for gear-inspection purposes; tending to favour dedicated machines instead. Furthermore, as the gear sector is a relatively closed market, many users opt for a GMI from the same supplier as their cutting machines, since it is difficult to access detailed information on the cutting cycles of a specific geometry corresponding to a large manufacturer of such cutting equipment. What this means on one hand is that evaluation is carried out in accordance with the same cycles and geometry as those of production, with optimum readings obtained; while it is on the other hand possible to connect both pieces of equipment - GMI and cutting machine - for the automatic correction of any measurement errors that might have arisen. It is nevertheless true, despite this circumstance, that both the GMI and CMM systems of measurement are increasingly tending to converge, offering very similar levels of performance [9]. Either of them is in any case capable, as an automatic system, of measuring and verifying the same parameters, thereby largely ruling out any subjective judgement on the part of the machine operator.

\subsection{Functional testing}

Functional trials offer another way to verify the accuracy grade of a gear. The special measuring procedures concerned allow parameters relating to operating conditions to be obtained. Measurement is not in this case based on continuous detection, but generally consists of comparing the rotating test gear to a conjugate master gear of better tolerance grade. If we assume a total absence of defects in the master gear, all deviations detected can therefore be attributed to the test gear. If certain parameters of the two gears are compared while they are turning, it is possible to pinpoint the accuracy grade of one gear alone or the complete pair [10], [11], while also obtaining geometric information based on the results. This has therefore traditionally been one of the most common ways of determining the accuracy grade of a gear, whether on the actual machine in the workshop (in the form of feedback obtained during production) or in the course of final inspection in a metrology laboratory. These tests are known as "rolling" tests, on the basis of how they are typically carried out, and are also referred to as being "composite", given that the results are not individually broken-down, uniform, geometric-parameter readings, but rather - on the contrary - the sum of various simultaneous influences. It is in fact possible to use tests of this type to pair off two gears, thereby identifying their optimum rolling performance, and even that of complete gear train, with quality-related readings that refer to the transmission as a whole rather than each separate gear. The benefits of rolling tests are clear, as their main objective is not to identify the geometry of a gear, but to verify its performance during operation. However, the task of breaking down the data obtained into the various influences involved is a complicated one, and in many cases impossible. 
There are two types of rolling test, referred to respectively as single-flank and double-flank testing or as tangential composite and radial composite testing. They are apparently very similar in terms of configuration and results, but they involve different measuring techniques and therefore different interpretations of the data obtained [12]-[14], as it is described in subsections 2.2.1 and 2.2.2. Both tests can be used to measure cylindrical, bevel and worm gears.

\subsubsection{Tangential composite inspection}

In the single-flank or tangential composite test, two gears are rotated along at their specified centre distance, subject to nominal geometric assembly conditions (Figure 5). One of the gears is motor-actuated and drives the other. The spindle of the driven gear is braked slightly, in order to ensure that the right- and left-hand flanks are in permanent contact with each other. This prevents the gears separating under the influence of inertia, which would falsify the results. These tests also need to be carried out at low speed, so that they do not affect, due either to vibration or to deformation, the dynamic aspects of the result. The rotational variation measured between the two gears is what constitutes the tangential composite deviation, known as the "transmission error".
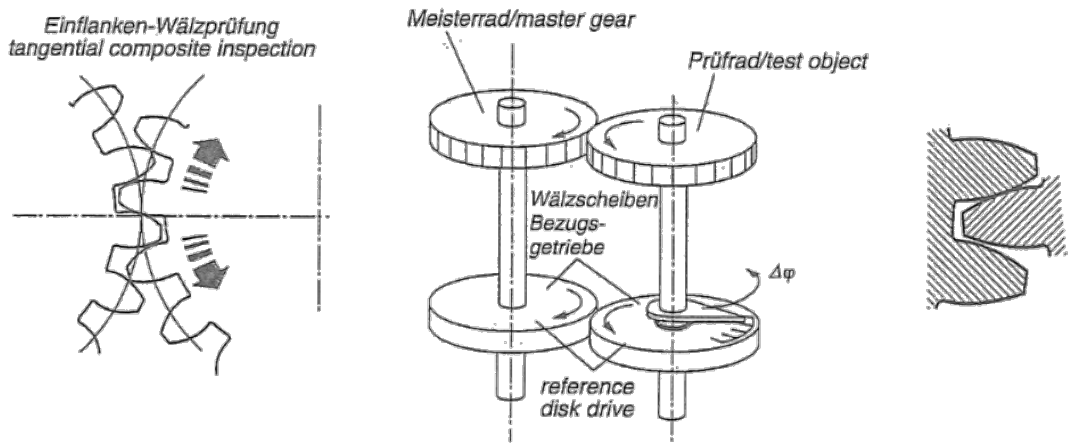

Figure 5.

Tangential composite test (source [12])

The single-flank rolling test carried out against a master gear ends as soon as the test gear has completed an entire revolution. When the test is carried out with two paired gears, the procedure must be long enough to ensure that they mesh together in all possible combinations [12]. The results obtained are normally expressed as a sinusoidal graph in which the abscissa is defined by the angle of rotation and the ordinate by the deviations in arc length relative to the reference diameter of the rotational variation between both gears (Figure 6). In cases such as these, transmission error may be indicated directly as an angle or even, in a circular manner, by the graph. The test results are evaluated in accordance with ISO 1328-1:2013 [10] or DIN 21772:2012 [15]. 


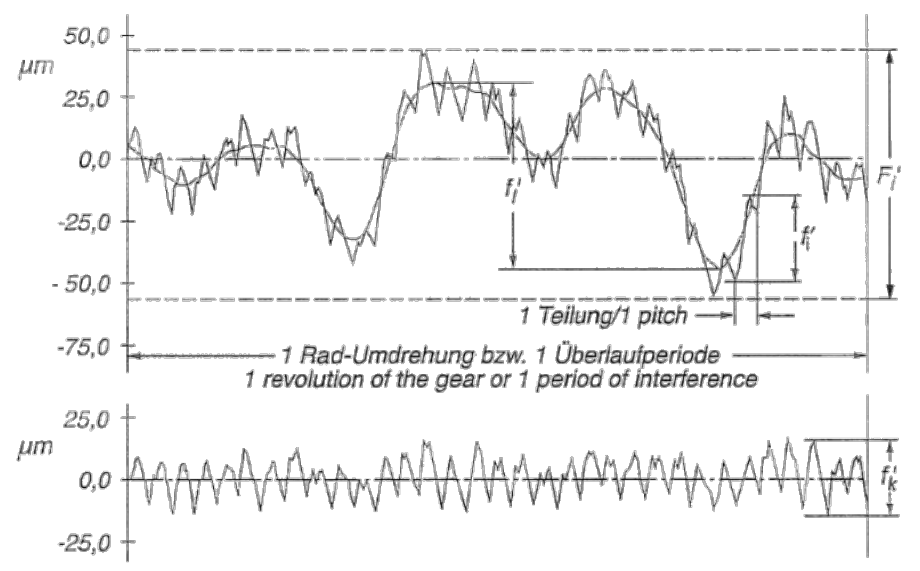

Figure 6. Evaluation of the tangential composite inspection (source [12])

The parameters of the composite tangential test, single-flank rolling test, which are evaluated on the basis of the measurement readings in order to determine the transmission errors of the gear, are as follows: the tangential composite deviation (Fi'), which is the difference between the maximum and minimum angular deviation in the course of one revolution or entire period, and the tooth-to-tooth tangential composite deviation (fi'), which is the greatest difference occurring for the angular deviations within the angle of rotation corresponding to the duration of a meshing.

A breakdown of the latter into their long- and short-wave components, using the Fourier transform, creates a further two: the long-wave component of the tangential composite deviation (fl'), which is the difference between the maximum and minimum value of the long-wave component of Fi', and the short-wave component of the tangential composite deviation ( $\mathrm{fk}^{\prime}$ ), which is the difference between the maximum and minimum value of the short-wave component of the results of the single-flank rolling test. The values fi' and fk' are frequently considered to be identical in actual practice, as there is barely any difference between them. The corresponding tolerance grade is most often assigned in accordance with the standards ISO 1328-1 [10] and DIN 3963 [16] for cylindrical gears, DIN 3965-3 [17] for bevel gears and DIN 3974-1 [18] for worm gears.

The study, understanding and interpretation of these parameters and graphs allow us to obtain information on variations affecting the profile, pitch, accumulated pitch and runout of a gear [19]-[23]. They also make possible a practical evaluation of behaviour, by permitting modifications designed to improve performance under future working conditions.

\subsubsection{Radial composite inspection}

In the double-flank rolling test, or radial composite inspection, the gears are forced to rotate without any free backlash. A variable centre distance is permitted for this purpose; adapted to possible cutting-related tooth deviations. The application of force in the direction of minimum distance ensures that the right and left- and right-hand flanks touch simultaneously throughout (Figure 7). At the same time, the force of the elastic system must not exceed a certain magnitude. This prevents possible deformations in the teeth from influencing the results [12], [14]. The maximum speed used in the test should also be limited in order to avoid possible dynamic effects with respect to the system. The test involves measuring the oscillations that correspond to the centre distance, which constitutes the radial composite deviation. 


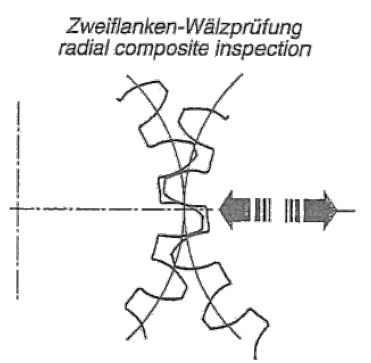

Figure 7.
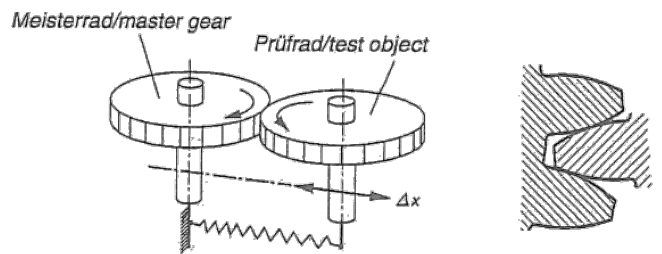

As with the tangential test, once the test gear has completed an entire revolution (in tests involving a comparative master gear) or a full period has been completed (pairs of production gears), the readings obtained are presented in the form of a sinusoidal graph. In this case, the abscissa is defined by the angle of rotation and the ordinate by the variation in centre distance of the two gears (Figure 8). The test results are evaluated in accordance with ISO 1328-2:1997 [11] or DIN 21772:2012 [15].

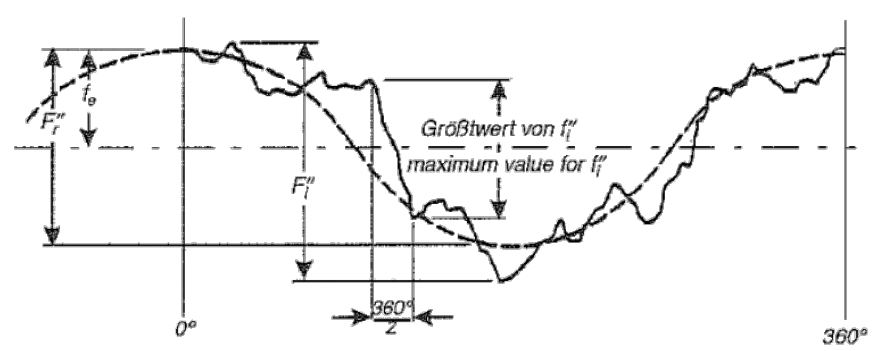

Figure 8. Evaluation of the radial composite inspection (source [12])

With respect to the centre distance without any backlash (a"), representing the displacement of the gear being examined, the double-flank rolling test involves the definition of two parameters: the radial composite deviation (Fi'), which is the difference between the maximum and minimum centre distance within one revolution of the test gear, and the tooth-to-tooth radial composite deviation (fi'"), which is the greatest difference of the centre distance occurring within an angle of rotation corresponding to the pitch.

The runout by composite test (Fr") is the long-wave component in the checking diagram for the radial composite deviations (Figure 8). It is obtained by the difference between the maximum and minimum value of the longwave component of $\mathrm{Fi}$ ". On the other hand, although some device manufactures calculate $\mathrm{fk}$ " as short-wave component of the radial composite deviation, this parameter is not defined in the standards. In contrast to the tangential tests, the assignment of a accuracy grade in their radial counterparts is practically reduced to the standards covering cylindrical gears, i.e. ISO 1328-1 [10], ISO 1328-2 [11] and DIN 3963 [16], with the sole exception of ANSI/AGMA 2009-B01 [24], which applies exclusively to bevel gears.

The double-flank rolling test offers sufficient information about the effect of the individual deviations of each tooth, and allows us to evaluate of rolling performance; while quickly detecting production problems, maladjustment or incorrect positioning in the cutting machines. At the same time, and thanks to this factor, it is possible to identify errors affecting the tooth thickness, the eccentricity of the cutting operation and incorrect pressure angles on the basis of periodical tendencies in the results; and to relate permissible deviations indirectly with the fitting tolerances of the centre distance [5], [6], [20]. 
The results of the tangential and radial inspections cannot be compared to each other, as they are based on different principles. Although the tangential test supplies much more information about functioning properties, the radial test is more widely used on economic reasons, and its informal content is sufficient for its purpose [12], [19], [20].

\section{Rolling tests: the state of the art}

Functional verification equipment was likewise developed in the 1920s, in parallel with the industrial launch of the first devices capable of measuring the involute tooth profile [1], [2]. As US patent 1,554,646, registered by C. Olson in 1925 shows [25] (Figure 9), the machines of the time began to be fitted with typical rolling-testrelated items such as springs, slide elements and fiction discs.

By the 1950s, and as a result of the Second World War [26], the increased demands placed on transmission systems forced the control procedures used for gears to improve, giving rise to what are now regarded as the first automatic measuring machines. According to US patent 2,687,576 [27] of 1954, Carl W. Mahr had already developed an automatic verification machine, based on the principle of the single-flank rolling test, which was able to measure differences in angular velocities between a gear and its corresponding master gear. It was also able to solve the familiar problems with the detection of small angular variations arising from the inertia of the system itself.

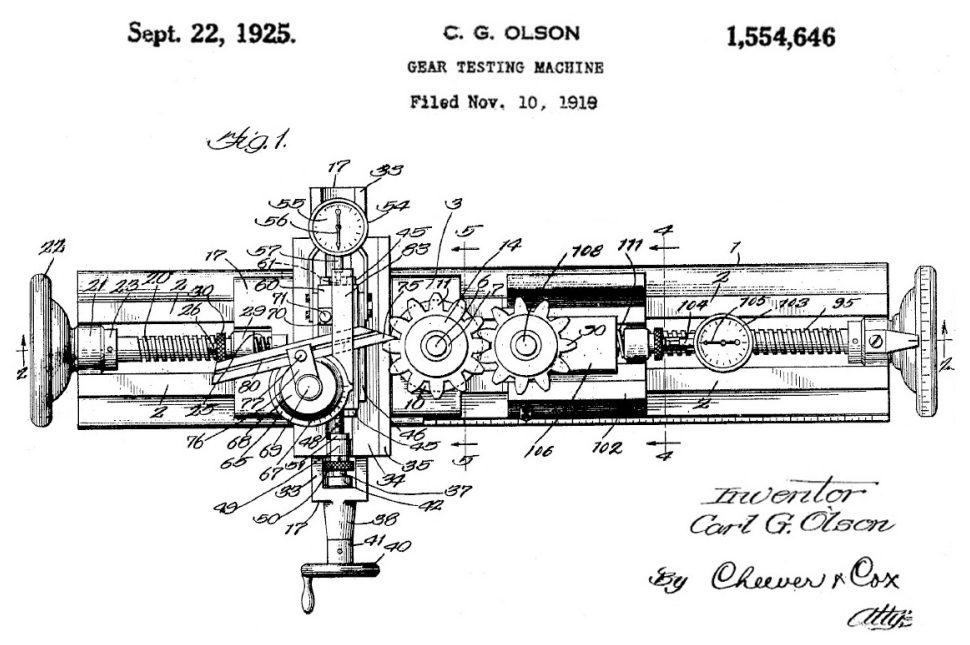

Figure 9. $\quad$ Example of patent for functional-testing machines (source [25])

These developments have continued to date, with many patents proposed over the intervening decades to confirm the interest in and usefulness of such rolling tests. Examples include U.S. patents 3,031,765 [28], from 1962, and 3,583,072 [29], from 1971, registered to a Swiss citizen named Müller, who proposed a design of single-flank rolling test machine that allowed the same friction discs to be used for different transmission ratios, thereby reducing the size of the setup. US patent 4,550,508 [30] of 1985, registered to his fellow Swiss citizen Hans Spaeth, then an employee of the Maag Gear-Wheel and Machine Company Limited, included an automatic alignment system between the gap of one gear and the tooth of the other, thereby making its application interesting for the verification of production lines. In 1997, a Japanese engineer named Matsumoto developed what was to be registered as US patent 5,689,993 [31], in which he proposed a calibration method for items of double-flank equipment using less-precise (and therefore cheaper) master gears, with a number of teeth that did 
not match the conjugate gear. In US patent 6,766,684 B2 [32] from 2004, Bertz and Golder, two Germans working on behalf of Klingelnberg Sohne $\mathrm{GmbH}$, replaced the elastic system with a linear motor designed to control to-and-from movement in a double-flank test rig. Finally, US patent 2014/0088891 A1 [33], developed in 2014 by Taiwanese researchers Chen and Lo, of the National Central University, defined a method for evaluating meshing performance with better precision, representing an improvement on the results normally obtained with the Fourier transform.

\subsection{Laying the foundations}

According to a letter by Robert Munro, addressed to the editor of Gear Technology [34] in 2004, the concept of transmission error was identified by a Cambridge University professor named Stephen Harris, who Munro was fortunate enough to have worked with from 1957 to 1964, during the latter's early research career. The two collaborated on the publication of various papers that predicted the effects of tooth deviation when under load, and the vibrations likely to be generated. They were furthermore able to demonstrate variation in transmission error, relative to load, for various gear-profile shapes, and even developed the notion of involute correction as a way of reducing transmission error [35]. This paper as provided a basis, over the last 50 years, for the understanding of meshing and rolling properties. Subsequent to this, and continuing with the same line of research, R. Munro [19] carried out theoretical and experimental studies in 1969 of single- and double-flank rolling tests, and concluded that further in-depth work was required in this respect.

Parallel to this, and likewise in 1969, Guenter [36] explained tests of this type and compared them to others of a more conventional nature. In 1972, Anon [37] demonstrated the advantages of using this system not only for different types of gearing, but also for complete transmissions, in Goulder-Mikron rigs that proved to be pioneering in the use of optoelectronic equipment to measure transmission error [34]. Tests using a new singleflank machine with increments of up to 10,000 were carried out on hobbed and ground gears in 1977 by Ishibashi et al. [38], who observed that there was scarcely any deviation in the recording stylus after the first revolution of the test gear. They also carried out studies of surface durability while subjecting one of the gears to a small amount of axial displacement.

It was in 1979 that Munro presented a complete revision of the method of single-flank evaluation [39]. Both this work and the previous endeavours carried out in collaboration with Professor Harris were published over the years as technical papers for presentation to the American Gear Manufacturers Association (AGMA). Using these publications as a basis and starting in 1984, Robert Smith, who was at the time working on behalf of the Gleason Company, published various papers that sought to simplify the interpretation of single-flank rolling tests. This was despite their complexity, which arises from the large number of parameters and influences present, including - for example - the vibrations generated, the levels of precision required or the difficulty inherent in analysing data using the Fourier series. His main objective was the practical application of this technique, which was at the time more widespread in Europe than in United States, in order to evaluate gears in a way that was valid for a large range of gears: cylindrical (spur and helical), bevel and worm gears.

In his article of 1984, entitled "What single flank measurement can do for you" [20] and published by AGMA, R. Smith focuses on the notion that a single-flank rolling test is much faster and more complete than all other individual tests. The results of a single test demonstrate rotational uniformity or precision during the meshing operation. These readings are directly related to variations in profile, pitch, accumulated pitch and runout. It is possible to verify most of the quality-related factors of a gear, with the exception of tooth alignment, despite the 
influence of other transmission errors resulting from profile variations. Smith includes, by way of example, illustrations showing both the typical shapes of teeth and their possible movement curves when rotated against a perfect gear, as with the interpretation of pitch variation. Figure 10-a shows the absolutely straight line generated by a perfect involute. In Figure 10-b, the crowning curve is a consequence of the modified tooth, with a degree of deviation approaching zero whenever contact takes place near to the reference circle, but which augments with increasing separation from both the root and tip of the tooth. Figure 10-c shows a ramp caused by a change in the pressure angle.
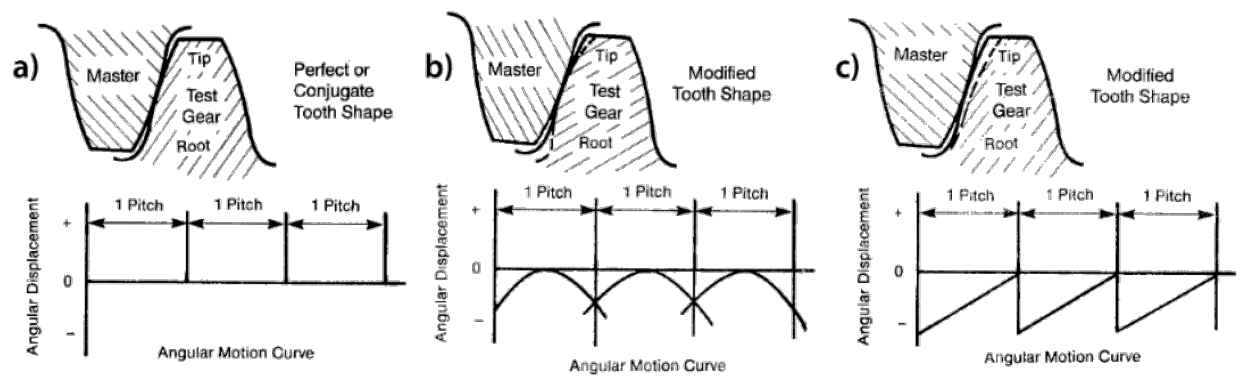

Figure 10. $\quad$ Examples of displacement curves (source [20])

Detection of variation in pitch and accumulated pitch can be observed in the resulting graphs. Figure 11-a demonstrates the effect in a single tooth, while Figure 11-b shows the accumulated total for each adjacent tooth.

a)

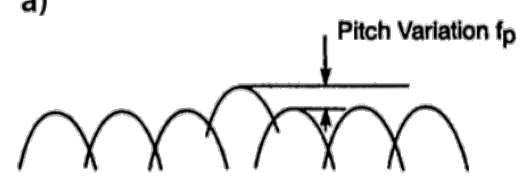

b)

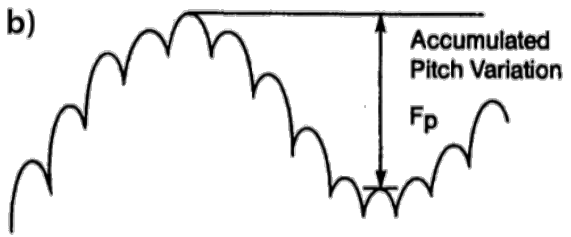

Figure 11. Interpretation of pitch variation in a single-flank test (source [20])

While referring to Munro's 1969 paper entitled “Effect of Geometrical Errors on the Transmission of Motion between Gears" [19], Smith adds the advantages of single-flank rolling tests relative to their double-flank counterparts. Although the double-flank rolling test is faster and cheaper to perform than its single-flank equivalent, it is normally impossible to interpret data on an elemental tooth-by-tooth basis, as both flanks are in contact simultaneously. The single-flank test provides a direct transmission-error reading, given that only one flank is in contact, thereby making it possible to interpret the resulting curve in terms of both profile and pitch deviation. When it comes to the limitations of rolling tests, Munro concludes that (i) there is not always a direct relationship between the readings from both tests, that (ii) identical results curves for double-flank tests can arise from quite different types of profile deviation, and that (iii) despite all the information obtained from singleflank testing, it only shows the profile deviation of the point of contact, and not that of the entire flank.

In this article, Smith provides material subsequently included in later publications entitled, respectively, "Identification of Gear Noise with Single Flank Composite Measurement” [21] (from 1985), "The Relationship of Measured Gear Noise to Measured Gear Transmission Error" [22] (1987) and "Solving Gear Noise Problems with Single Flank Inspection" [23] (1990), all of which discuss the link between gear noise and transmission error. Smith's intention with these publications was, as in the previous case, to provide a guide to solve the 
annoying problems of noise associated with single-flank rolling tests. After carrying out single-flank tests, the tooth-to-tooth element is related to noise and vibrations, while problems with precision are related to rotation. Each one of these components can be isolated by the application of low- and high-frequency filters, while using the Fourier transform for subsequently determining the corrective action to be applied to the teeth. The data concerned are often too complex to be analysed by analogical means (determined by time), due to causes such as the presence of burred edges, excessive amplitude or modulation frequency, the appearance of notches in the teeth or the eccentricity of the pinion. It is more useful in such cases to carry out a real-time frequency analysis based on analogical data, by converting these data into individual frequencies (Figure 12) relative to the various geometric elements of the gear.

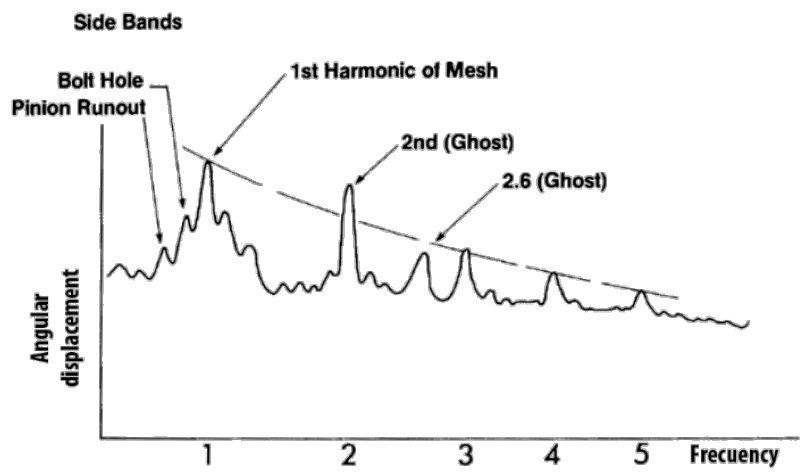

Figure 12. $\quad$ Frequency spectrum (source [21])

According to R. Smith, W. Mark [40] breaks the frequency spectrum down into two components. One of these elements is average geometric deviation, defined as the tooth surface formed by the average surface of all the teeth being examined; while the other element is random geometric deviation, defined as the surface deviation of a tooth with respect to the average. The former, which arises from deliberate or accidental modification of the profile, provokes gear vibration harmonics; while the latter, which arises from the effects of runout, provokes rotation harmonics.

One important attribute of the single-flank rolling test is its ability to verify variation in accumulated pitch which, together with the detection of runout, is another factor to which Smith pays special attention, as demonstrated by the extended studies in his papers entitled "What is Runout, and Why Should I Worry About it?" [41] and "Detection of Hidden Runout" [42], from 1991 and 1995 respectively. Runout, which makes itself apparent in a gear whose surface is eccentric relative to the reference circle, turns out to be the major variable factor in the composite deviations that arise during single-flank testing. It creates problems that are likely to affect the other characteristics of a gear (including involute shape, pitch variation and tooth alignment), while generating vibrations, noise and a lack of precision affecting transmission; all of which make it a factor worth keeping under control at all times. On the other hand, although runout is a radial phenomenon, there is also hidden runout; another way of expressing accumulated pitch variation of tangential origin. It is for this reason that this deviation cannot be detected using conventional ball- based inspection techniques or double-flank rolling tests. A gear with runout has accumulated pitch variation, while one without runout has accumulated pitch variation resulting from eccentricity at some stage in its production process. Smith uses a simple mathematical approach to attempt to explain the data obtained from gears with "hidden runout", to quantify the relationship between the conditions that cause it and the results of inspections and, finally, to discover how to 
interpret the results in a way that differentiates it from conventional runout. This is done by expressing, as a mathematical formula, the deviation produced by a variation between the centre of the finished gear and the centre of the hobbed gear (Figure 13), resulting in an angular deviation of the point of contact with respect to each of the centres.

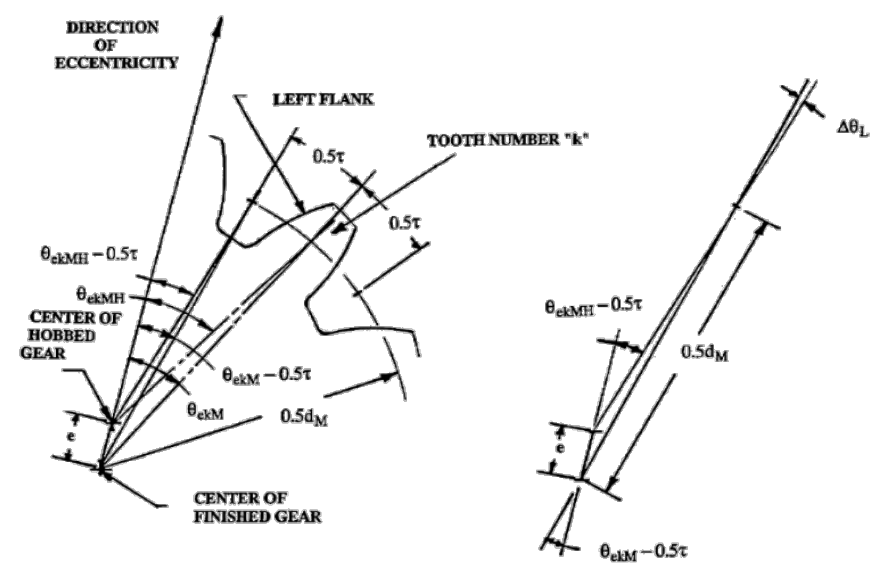

Figure 13. $\quad$ Angular locations of hobbed and finished tooth gaps as per Smith (source [42])

He concludes, after carrying out gear tests using different machining and finishing procedures, that radial measuring systems actually provide misleading runout readings (Figure 14), which means that they are only useful at certain stages of the manufacturing process, and are not sufficiently reliable for final quality-control purposes.

Finally, he highlights the importance of avoiding eccentricity, both at the rough machining stage and during the attachment of components in each subsequent phase, all of which generate "hidden runout", given the erroneous belief that it can be dealt with at the finishing stage. The corrective action concerned can only be applied to one side of the gear teeth, so its usefulness is limited to one turning direction only. What Smith suggests overall is that the standards of gear quality should not employ runout as a reference parameter, but should rather specify the use of accumulated pitch variation.
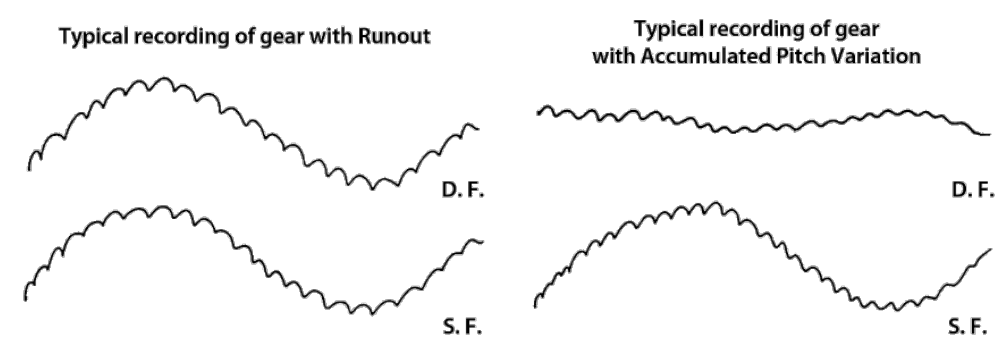

Figure 14. Typical results of rolling tests with runout and accumulated pitch (source [20])

\subsection{Evolution and current practice}

There is not exactly an abundance of publications regarding rolling tests, despite the fact that they are highly useful and widely employed in the gear industry as a fast and thorough means of verification. There has nevertheless been a tendency, since 2008, for increasing numbers of specific research groups to focus on the subject. While it is certainly true that more knowledge is being generated by producers of gear manufacturing 
machines, those dedicated to verification and inspection and the gear manufacturers themselves, the information produced is limited to in-house distribution. We have already seen how people such as Harris, Munro and, more recently, Smith wished to assist in the task of interpreting and understanding the results obtained. Their publications have in any case laid the foundations for current studies and development work being carried out by various groups, and for functional rolling tests. This section reflects this, and the influence exercised and contributions made are appreciable.

Using the traditional, single-flank rolling test as a starting point, Zhang et al. [43] developed, in 1997, a new gear-measuring system that made use of a special mater gear with three different types of measurement teeth and one corresponding to transmission (Figure 15). With this method, a different deviation is verified with each tooth: profile deviations, lead deviation, tangential composite deviation and pitch deviations. Based on a comparison between the experimental results obtained by the new approach and measurements carried out on a Zeiss VG450 machine, this method has proved to be feasible. Nevertheless, the deviations in the master gear exercise considerable influence, which makes it necessary to carry out low-speed tests with limited load in order to avoid wear; and also to keep the contact surfaces completely clean for the maintenance of proper testing conditions.

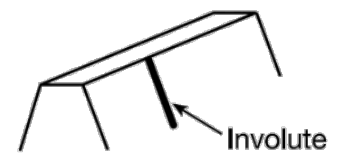

(a)

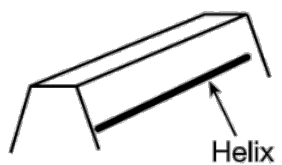

(b)

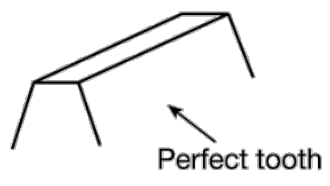

(c)

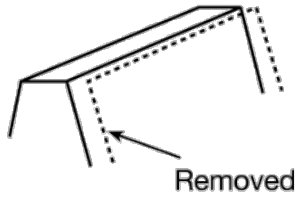

(d)

Figure 15. Example of the four types of tooth (source [43])

Edward Lawson, of the Mahr Corporation, dedicates a short section of his 1998 publication on the metrology of gears [5], [6] to a comparison of the benefits and drawbacks of rolling tests. He stresses that although the doubleflank rolling test provides less information, it may prove useful in the detection of non-systematic defects such as notching, burred edges or minor impact damage, thereby supplying a rapid functional evaluation of the teeth concerned.

Back in 2004, a German company called Frenco GmbH patented and launched a new type of functional testing machine based on rolling techniques named "Rollscan" [44]. A special master gear composed of tooth components, which are at the same time probe elements in contact with different parts of the flanks of each tooth, makes it possible to identify with precision the flank's line of contact. The secret of this system lies in the scanning of different parts of the flanks of each tooth with a contact ratio of less than 1, thereby separating the individual deviation corresponding to each tooth. Although this method is effective, its use is limited by the complexity of the master gears, by difficulties arising from the processing of scanned surface data and by the test speeds that result from having to perform as many revolutions as there are teeth to verify.

Richard Thoen pointed out, in 2008, how historical evidence shows that tooth-to-tooth radial composite deviations measured in double-flank rolling tests differ from one machine to another [45]. Although he is aware of the fact that the calibration of this type of equipment is unlikely to become widespread in the near future, he proposes a method that allows these deviations to be monitored by means of a pointed-tooth master gear, in order to generate known tooth-to-tooth radial composite deviation. 


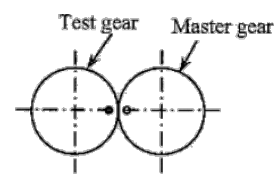

(0)

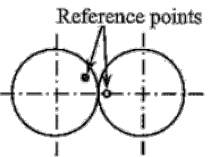

(1)

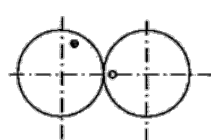

(2)

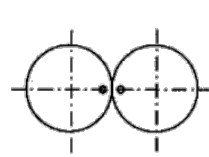

(M)

Figure 16. Multiple-step error separation technique for a gear pair (source [46])

In the same year, Guo et al. established two different techniques to try and separate the deviations arising from double-flank rolling tests [46], by means of a mathematical formula and corresponding experimental checks. The first of these, which uses two gears (master gear and test gear), is based on a multiple-step error separation technique, which in turn involves rotating the fixed reference of a master gear (Figure 16) with respect to all the possible positions of the test gear. The harmonic readings obtained in the Fourier series [47], [48] reveal that this method can only be used to separate the total radial composite deviation (Fi'), but not the tooth-to-tooth radial composite deviation (fi"), because deviation of the master gear contains, along with its harmonics, those corresponding to the test gear, the value of which is the main factor affecting tooth-to-tooth deviation.

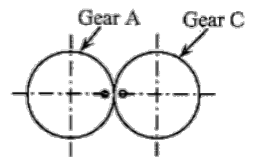

(a)

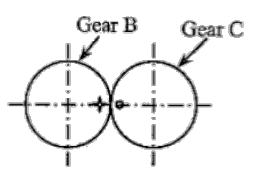

(b)

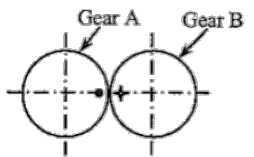

(c)

Figure 17. Schematic of the three-gear error separation method (source [46])

Three gears are used in the second technique, three-gear error separation method. They are made to rotate two at a time, starting from the same reference point for each one (Figure 17). It is possible in this case to separate the total radial composite deviation and most of the radial deviation from tooth to tooth.

According to Chajda et al. of the Pozan University of Technology, there is, despite the many publications and conferences dedicated to the search for a more accurate way of making gears, still no complete theoretical description of what constitutes gear precision. Their contribution of 2009 made in this respect consisted of relating the influence of geometric errors in gears to their dynamic performance, on the basis of single-flank rolling tests [49]. The results, both simulated and experimental, reveal that pitch deviations are the main influencing factor, affecting some $80 \%$ of dynamic variations. The impact attributable to eccentricity is approximately $20 \%$, while less than $1 \%$ is caused by deviation affecting the base radius.

After using simulation of double-flank rolling tests applied to the concept of analysis by tooth contact, Taiwanese researchers Liu and Lin proposed, in a paper published in 2009 [50], a significant process for establishing the analysis aspects and capacities of such tests. Using as a starting point the geometric gear formulas of Litvin [51], [52] and the functional-test studies carried out by Munro and Smith [20]-[22], [39], [53] in the $1980 \mathrm{~s}$, they carried out a simulation of straight-toothed cylindrical gears. They use various graphic examples to illustrate possible results, as they modify and combine different parameters, such as pressure angle and/or eccentricity. They feel that these results could be used to trigger future research into double-flank rolling tests. 
A 2010 proposal from DaLian University of Technology in China includes a new design of machine for the radial composite testing of high-precision master gears [54]. This instrument uses a spring-suspension configuration (Figure 18) to deal with the drawbacks arising from major rotation errors, low sensitivity and large amounts of force, in the manner in which they are present in traditional inspection machines; while increasing precision with the elimination of fiction-based shock absorption. After carrying out additional corrections to the angle of the system of springs, the eccentricity of the master gear, the parallelism of the axes and softwarecontrolled spring strength, Yong et al. obtained test results with an uncertainty factor of $1.4 \mu \mathrm{m}$, thereby guaranteeing the possible use of master gears of accuracy grade 2 .

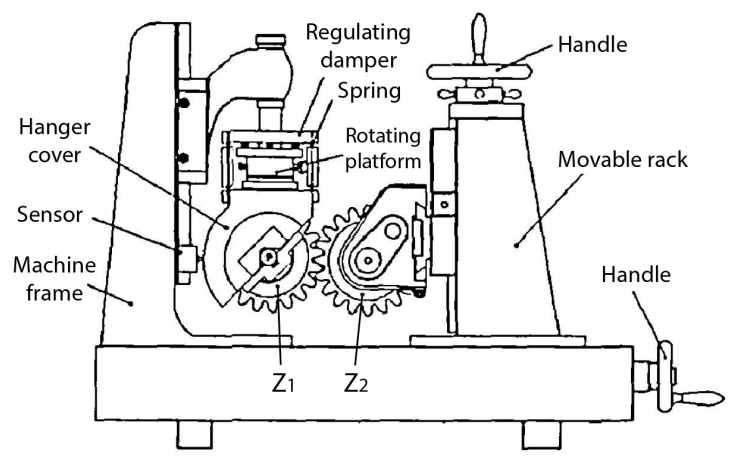

Figure 18. $\quad$ The radial composite testing machine designed by Ma et al. (source [54])

In order to improve the inspection methods employed in the batch production of fine-pitch gears (i.e. with modules from 0.05 to 0.5 ), the Chengdu Tool Research Institute of China collaborated in 2010 with the company Scan Direct Ltd on the development of a piece of equipment based on the single-flank rolling test and integrated gear-error measuring technology. They used a special master gear to verify not only tangential deviation, but also the elemental profile and pitch deviations present in gears of this type [55]. Huakun et al. succeeded by using two synchronised axes and a differential measuring cycle, along with a conventional master gear fitted with teeth that become narrower along the length of the profile. They nevertheless concluded that there was a need to improve precision and create a way of measuring helical deviation.

M. Cui and W. Deng of the Sun Yat-sen University in China developed, in 2012, LabVIEW-based software designed to separate the different components that constitute the radial deviation of a gear, using as a starting point the data obtained from a conventional double-flank testing machine [56]. As the radial components are periodical, the error separation techniques could be used to break down the data as a total of the harmonics of the different periods and measurements of dynamic errors. Most sources of error, such as the friction coefficient of the floating carrier, the pushing force between gears, the tension in the drive belt, the precision of sensors and the integration of hardware, along with other factors, can be detected for subsequent correction, although it is impossible to eliminate all sources of external interference.

In 2013, Pueo et al. [57] conducted a mutual comparison of various double-flank testing machines, which failed - despite the repeatability of each of the items of equipment concerned and the maintenance of consistent test conditions - to obtain the same results between one machine and another. They pointed out a lack of clear standards with respect to the calibration of this type of machine.

Early in 2014, Ernie Reiter and Fred Ebarle, both of them members of the technical committee of AGMA, published a two-part series of practical considerations regarding the use of double-flank rolling tests to monitor 
the manufacture of gears [58], [59]. They described the test theory in the first part, giving details of the equipment used, defining the measurement readings that can be obtained, revealing the calculations involved and also explaining the interpretation of possible results. They insist on the idea that these tests are very good for determining the quality of the production process used for gears, and for identifying potential errors, albeit without being able to use them to establish individual effects with any precision. They use the second part to describe how statistical techniques are applied to verify the stability of the production process for large-volume batches of gears, based on practical and economic double-flank testing. Despite having carried out statistical analysis of variance in the repeatability and reproducibility of the tests (ANOVA gauge $R \& R$ ), they conclude that uncertainty analysis offers a much better way of dealing with the dynamic measurements obtained with tests of this type. Imperfections in contact surfaces, the accumulated effects of measurement, the number of readings and the automation of the system itself, along with other factors, make it impossible to quantify each and every one of the influences that are likely to affect the results of an ANOVA study.

Carried out virtually in parallel with the above studies in the first decade of the century, the initiatives conducted under the leadership of Professor Shi of the Beijing University of Technology, a member of ISO/TC 60, are the factors that have contributed most to the functional tests referred to here. In 2008, they presented a double-flank rolling-test rig with many degrees of freedom that incorporated two master gears to obtain both radial and tangential parameters, including radial composite helical taper and slope deviation, in the course of a single inspection [60], [61]. The simplicity and increased efficiency of these double-flank tests, coupled with the measurement of new changes using linear sensors (Figure 19), could satisfy the growing demand for high-speed gear inspections, on the actual production line, for large-volume production batches. Results published since 2011 have been concerned with the repeatability of the machine [62], while emphasising the number of influences that are likely to affect the measurement result, and which need to be taken into account when trying to conduct all tests under the same working conditions.

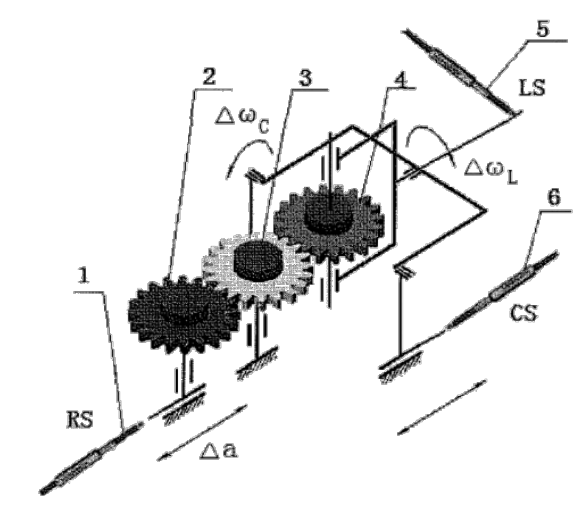

Figure 19. Schematic illustration of Professor Shi's machine (source [60])

The year 2008 likewise marked the appearance of another publication dealing with the development and application of double-flank rolling-test technology [63]. This included a detailed analysis of the different methods based on this measuring principle, before concluding with an introduction to new methods and existing tendencies.

Analysis carried out in the same year looked into insufficiencies affecting single-flank rolling tests, and proposed corrective action based on Zhang's "integrated error" method [43], applied to the master gear as a way of verifying a pair of gears [64]. A gear-pair integrated error curve (GPIEC) can be used to represent all the errors 
as a group, in a way that ensures that the deviations affecting all points on the flanks of the conjugate teeth have the same reference (Figure 20). The intention is to use theory-based deduction, the formula definition and presentation of the method to allow GPIECs to be used not only to verify the quality of the transmission, but also to analyse sources of error and noise. The belief is that this GPIE concept could have future influence on tolerance standards and the methods of error analysis applied to production, and that it could even open up new avenues of research into the dynamic characteristics of gears.

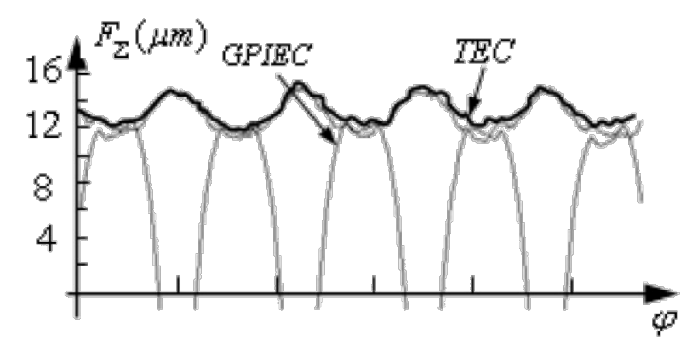

Figure 20. Comparison between GPIE and transmission error (source [64])

Between the years 2009 and 2011, Shi et al. went on to develop a prototype designed to inspect fine-pitch gears [65], [66], based on the principle of the single-flank rolling test. The test rig, which consisted of two synchronised vertical axes, was similar in design to the rig being developed in parallel and during the same period by Xie et al. [55].

In 2012, Shi's team proposed a new system for evaluating profile deviation based on application of the principle of the double-flank rolling test, for the purpose of high-speed inspections carried out directly in the workshop [67], [68]. This method measures movement in the radial and tangential direction at the same time with a rack probe (Figure 21), while it meshes with the test gear - without any backlash in a double-flank testing machine. Apart from the high speed of the test, this system removes the need to make costly, high-precision master gears.
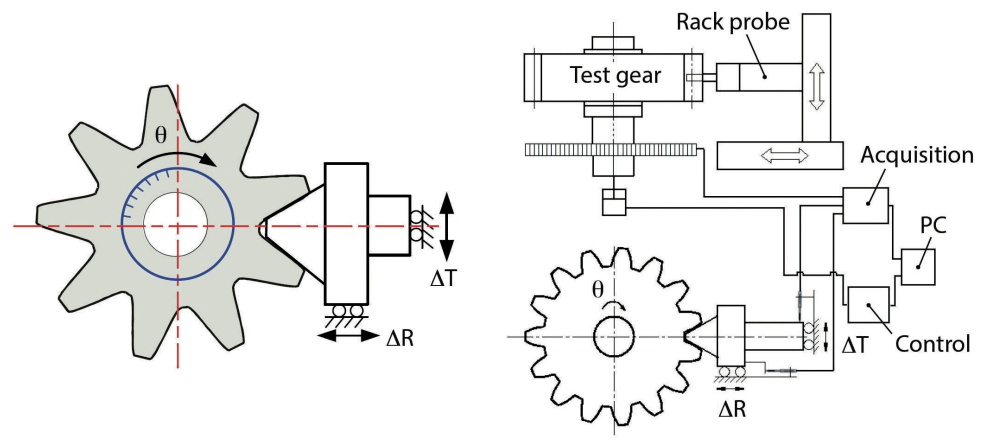

Figure 21. $\quad$ Structure of the novel measuring system with a rack probe (source [68])

The final project of the Shi group carried out to date and worth mentioning here concerns the design and development, carried out in 2013, of a piece of equipment (Figure 22) based on the principle of the single-flank rolling test and used to calculate transmission error in face gears [69]. A method that involves counting the subdivisions of high-frequency clock pulses is used to obtain readings for tangential composite deviation, pitch deviation, backlash and eccentricity in gears of this type. Despite the lack of a set of standards for such gears, the authors use, as a reference for evaluating precision, the standards applying to bevel and hypoid gears. After 
conducting various tests, they carried out an estimate of the machine's uncertainty in order to determine the maximum accuracy grade of measurement readings.

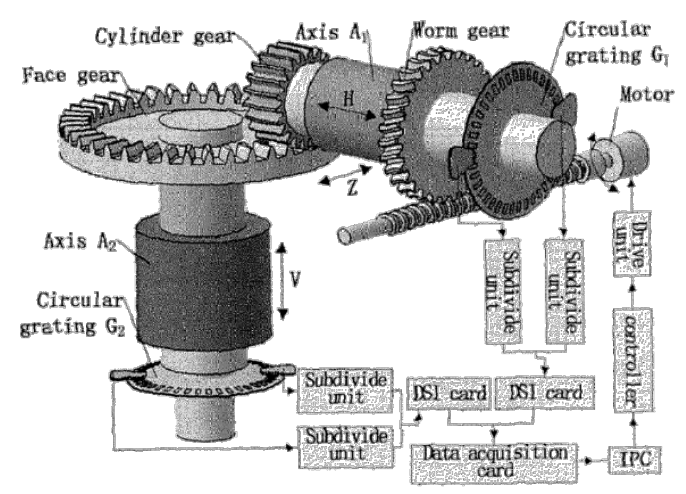

Figure 22. Schematic view of a rig based on the single-flank rolling-test procedure for face gears (source [69])

\subsection{New applications}

It is clear, given the growing use of portable multi-function electronic devices that more and more micro mechanical components are going to be needed. This micro-sizing of mechanical components nowadays frequently applies to the gears that form part of the miniature actuators and transmissions fitted to dental, surgical and optical equipment, or to metrological instruments - all of which have to be tested and validated in some way or another.

Although it continues to be ambiguous, the term "micro gear" can probably be applied to any miniature gear mechanism that includes key functioning elements, such as pitch or module, with dimensions that fall within the micrometric range [70]. The development of different verification techniques is meanwhile taking place once again in parallel with corresponding progress in the field of microfabrication. Traditional techniques are being evaluated, in addition to the creation of new measuring systems, in order to check their validity. Rolling tests could prove to be beneficial in this respect, given their functional nature.

In 2008, Albers et al. proposed the use of tangential and radial composite inspection for gears used in micro mechanisms [70], given the lack of any other suitable method at the time. This entails the adoption of defined standards for macroscopic gears, whose use is proposed for the special needs and operating conditions of microtechnology. As it is not possible to guarantee the minimum quality required for a master gear of these dimensions, results are obtained by testing various gears in different positions. This work is at the same time complemented by a comparative examination of experimental radial rolling tests (Figure 23) and a simulation of the same in terms of finite elements, before concluding that simulation can be simplified by moving from 3D to 2D [71]. They subsequently published (in 2010) work along the same lines; this time involving simulation of tangential rolling tests [72]. 


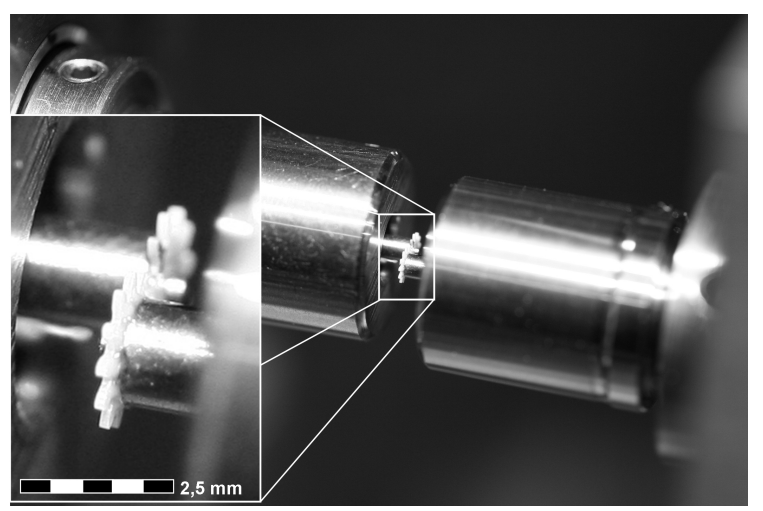

Figure 23. Radial composite test for micro gears (source [71])

In 2010 Du et al., of the Jiu Quan Statellite Launch Center in China, proposed a system for the geometric measurement, based on static images, of straight-toothed cylindrical micro gears, and also considered the possibility of carrying out integrated dynamic measurements [73]. It is possible, using perfect rolling performance as a basis, to create a virtual single-flank rolling test in order to predict the behaviour of a gear pair, by simulating how they actually mesh with each other.

The Metal Industries Research \& Development Centre in Taiwan developed, in 2011, a prototype rig for carrying out double-flank rolling tests. It was designed to meet the need to verify gears with a reference diameter of $1.56 \mathrm{~mm}$ and module of 0.12 used in micro planetary-gear mechanisms [74], as there were no commercially available machines capable of handling gears of these dimensions. It is possible, despite the fact that international standards do not include such small dimensions in their tables [10], [11], to use simple formulas to calculate the corresponding values for each characteristic in terms of module and reference diameter. The accuracy grade of the micro gears was finally determined with composite functional tests that used a master gear with a much larger tooth number than the test gear.

As a response to the lack of commercially available equipment, Acero et al. presented [75], in 2013, a doubleflank, rolling-test machine for cylindrical gears with reference diameters ranging from $1 \mathrm{~mm}$ to $10 \mathrm{~mm}$ and a module of up to $100 \mu \mathrm{m}$. The publication gave details of the actuating components (including a servomotor with maximum torque of $2 \mathrm{mNm}$ ), and also the elements used for measuring and for positioning of the centre distance and its variations during the test, with an obligatory minimum resolution of $0.01 \mu \mathrm{m}$ in each case.

\subsection{Standards applied}

Several sets of standards are employed in the gear sector, with varied usage and application throughout the world. There is normally no direct correlation between one set and another, making it impossible even to carry out analysis in a standard way, which gives rise to differences in basic tolerances [76] (see Figure 24). Any comparison between them would require a specific evaluation of the characteristics of individual parameters, while taking care to translate the terminology from one language to another in a manner that conforms to the standards drawn up in the source languages concerned. 

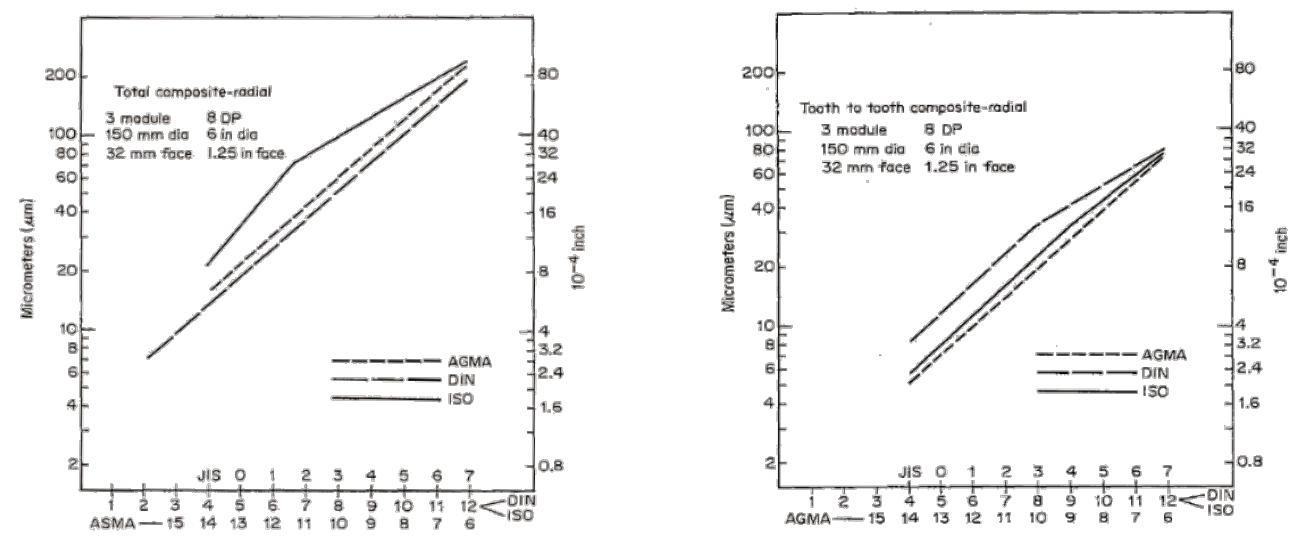

Figure 24. $\quad$ Comparison of the standards applying to radial composite testing (source [76])

There has nevertheless been, thanks to the creation of the ISO/TC 60 working group, a worldwide tendency favouring the standardisation of gears. This task involves joint collaboration on the part of internationally renowned members of the world's main standardisation organisations and associations [77]. The corresponding technical committee is manned by the American National Standards Institute (ANSI), the Deutsches Institut für Normung (DIN), the Japanese Engineering Standards Committee (JISC), the British Standards Institution (BSI) and up to 14 more participating countries, along with 23 countries with observer status. This initiative is intimately linked with vital work being carried out by associations of engineers and gear manufacturers, such as the Verein Deutscher Ingenieure (VDI) or the American Gear Manufacturers Association (AGMA), which have for several years been defining standards based on the actual experience of manufacturers and users.

Curiously, and despite the uniformity of criteria and greater clarity in terms of parameters and tolerances that results, the actual standards continue to recommend that customers and manufacturers of gears reach previous agreement regarding the maximum values that are to be admitted during the manufacturing process, in accordance with their respective needs and capacities. This applies in particular to inspections based on rolling tests [10], [11], [78].

The drafting of the technical reports ISO/TR 10064-1:1992 [79] and ISO/TR 10064-2:1996 [80], compiled using different publications included on the basis of an international standard (i.e. type 3), subsequently gave rise to publication of the standards ISO 1328-1:1995 [81] and ISO 1328-2:1997 [11], which cancelled and replaced ISO 1328:1975 [82]. This establishes a system for determining the precision of the flanks of individual involute-tooth cylindrical gears, while defining applicable and appropriate terminology, the structure of the gear's precision and the permitted amounts of pitch, profile and helical deviations. There is now a new version of the first part, "ISO 1328-1:2013 Definitions and allowable values of deviations relevant to flanks of gear teeth" [10], whose continued objective is to provide a common standard for manufacturers and customers, with a view to creating consensus between them.

DIN suspended the final publication of various drafts to make a joint contribution to the ISO/TC 60 group. The result was the publication of the first international standard for gear concepts and geometries, ISO-21771:2007 [83] that withdrew the widespread DIN 3960:1987 [84] standard. Recently, DIN has supplemented the German version of DIN ISO 21771:2014 [85] with the standards DIN 21772:2012 [15] and DIN 21773:2014 [86] replacing completely in this way the former DIN 3960:1987 [84]. In parallel, AGMA carried out a complete 
revision of its standard entitled "ANSI/AGMA 2000-A88 Gear Classification and Inspection Handbook" [87], which had been used in the United States for many years to provide a system of gear tolerances, with barely any changes in the course of the previous four decades. The revision adapted it in conformity with ISO [88]. This resulted in publication of the standards ANSI/AGMA 2015-1-A01 [82] and ANSI/AGMA-2015-2-A06 [89], which include, for example, values based on the metric system. E. Reiter, an active member of several of AGMA's gear committees, nevertheless feels that improvements are required, as several aspects of the new standard are more complicated than their predecessors. Examples include the confusing way in which accuracy grades are listed and numbered, along with the exclusion and limitation of certain types of gear, along with other issues [90].

With regard to rolling tests, ISO 1328-1:2013 [10] includes the classification of gear accuracy grades for cylindrical gears in accordance with tangential composite deviations, or in other words the values permitted in the course of single-flank rolling tests. It also contains the evaluation of runout ( $\mathrm{Fr}$ ”), previously handled in ISO 1328-2:1997 [11], which has been brought back into this part of ISO 1328. ISO 1328-2:1997 [11], on the other hand, uses various formulas and tables to define values for total radial composite deviation (Fi") and tooth-totooth radial composite deviation (fi"), likewise for cylindrical gears. There are, in addition to ISO standards, various guidelines for rolling tests that merely cover the collection of tolerance values. They describe both types of rolling test, but fail to go into any detail regarding their corresponding magnitudes or the conditions in which they are carried out. As already indicated in section 2.2, the grade of bevel gears subjected to single-flank testing is determined in accordance with DIN 3965-3 [17], while DIN 3974-1 [18] applies to worm gears. There are on the other hand barely any standards that can be applied when determining the gear's grade based on double-flank tests. This is the case with ANSI/AGMA 2009-B01 [24], which only applies to bevel gears, while there is no standard at all for application to worm gears. There are even fewer standards that include a clear and concise description of the tests involved. Most of them, such as VDI/VDE 2608 [12] or AGMA 915-1-A05 [13] and 9152-A05 [14], which follow ISO guidelines, are merely recommendations, rather than descriptions forming part of a uniform standard. As a result of these circumstances, and depending on the region in which a particular standard is normally applied, the nomenclature is likely to be different and the evaluation of parameters can suffer slight variations.

On the other hand, only ANSI/AGMA offers standard recommendations that cover the evaluation and qualification criteria of rolling-test machines. ANSI/AGMA 2116-A05 [91] gives recommendations regarding the operating conditions of the measuring system, along with dimensional and geometric details of the devices used to calibrate double-flank testing machines. In addition to this, ANSI/AGMA 935-A05 [92] covers the operating conditions and alignment of the measuring instruments most likely to influence results, along with information on their calibration procedures. Industrial calibration solutions are already being proposed, in parallel to these standards, for application to equipment of this type on the basis of experimental results obtained with a master gear [93].

\section{Conclusions}

This revision of the current status of rolling tests shows the advantages of functional verifications in the context of gear metrology. Tests of this type do not just provide a faster and more direct way of verifying a gear in the light of its future operating conditions; they also allow us to detect errors in the actual manufacturing process, before the final quality control of the gear. Despite the fact that the techniques concerned have been in use for 
various decades, this paper reveals that progressive improvements in the precision of manufacturing systems, coupled with the emergence of microfabrication, have created growing interest on the part of various research groups in the use, with all types of gears, of both single- and double-flank rolling tests. Further study in this respect would in fact suppose an increase in the speed of inspection, along with deeper analysis of both the gears' accuracy grade and their production process. This document is therefore intended to be a guide for researchers interested in improving and further developing the functional inspections currently applied to the metrology of gears. A joint appreciation of the main standards applying to single- and double-flank rolling tests also reveals the need to unify the guidelines concerned so that they regulate more clearly the measuring parameters applied to different types of gear, along with the test conditions in each case and the calibration of the equipment used; with a view to establishing a uniform approach to traceability based on national points of reference.

\section{References}

[1] R. Och, "History of gear measuring machines and traceability 1900-2006," Gear Prod. News, no. October, pp. 20-25, 2006.

[2] Z. Y. Shi, Y. T. Fei, and H. K. Xie, "100 years of gear measurement technology-review \& prospect," Eng. Sci., vol. 5, no. 9, pp. 13-17, 2003.

[3] L. Gazzaniga, El Libro de los Engranajes: Tratado Práctico para el Cálculo, Trazado, Ejecución y Control de los Engranajes. Barcelona, 1961.

[4] D. Gimpert, “An Elementary Guide to Gear Inspection,” Gears Solut., no. June, pp. 32-38, 2005.

[5] E. Lawson, “The Basics of Gear Metrology and Terminology Part I,” Gear Technol., vol. 15, no. 5, pp. 41-50, 1998.

[6] E. Lawson, “The Basics of Gear Metrology and Terminology Part II,” Gear Technol., vol. 15, no. 6, pp. $67-71,1998$.

[7] G. Goch, “Gear metrology,” CIRP Ann. - Manuf. Technol., vol. 52, no. 2, pp. 659-695, Jan. 2003.

[8] W. Lotze and F. Haertig, “3D gear measurement by CMM,” in Laser Metrology \& Machine Performance V, WIT Trans., vol. 34, WIT Press, 2001, pp. 333-344.

[9] Mitutoyo America Corporation, “CMM Gear Inspection,” Gear Technol., vol. 30, no. 1, pp. 11-13, 2013.

[10] "ISO 1328-1:2013 Cylindrical gears - ISO system of accuracy - Part 1: Definitions and allowable values of deviations relevant to corresponding flanks of gear teeth." 2013.

[11] "ISO 1328-2:1997 Cylindrical gears - ISO system of accuracy - Part 2: Definitions and allowable values of deviations relevant to radial composite deviations and runout information." 1997.

[12] "VDI/VDE 2608 Tangential composite and radial composite inspection of cylindrical gears, bevel gears, worm and worm wheels." 2001.

[13] “AGMA 915-1-A02 Inspection Practices - Part 1: Cylindrical Gears - Tangential Measurements.” 2002.

[14] “AGMA 915-2-A05 Inspection Practices - Part 2: Cylindrical Gears - Radial Measurements.” 2005.

[15] “DIN 21772:2012 Gears - Cylindrical involute gears and gear pairs - Definition of deviations.” 2012.

[16] "DIN 3963:1978 Tolerances for cylindrical gear teeth - Tolerances for working deviations.” 1978.

[17] “DIN 3965-3:1986 Tolerancing of bevel gears; tolerances for tangential composite errors." 1986.

[18] “DIN 3974-1:1995 Accuracy of worms and worm gears - Part 1: General bases.” 1995. 
[19] R. G. Munro, "Effect of Geometrical Errors on the Transmission of Motion between Gears," Proc. Inst. Mech. Eng., vol. 184, pp. 79-84, 1969.

[20] R. E. Smith, "What Single Flank Measurement Can Do For You," AGMA, Washington, DC, Tech. Paper, 84 FTM 2, Oct. 1984.

[21] R. E. Smith, "Identification of gear noise with single flank composite measurement," AGMA, San Francisco, CA, Tech. Paper, 85 FTM 13, Oct. 1985.

[22] R. E. Smith, "The Relationship of Measured Gear Noise to Measured Gear Transmission Errors," AGMA, Rochester, NY, Tech. Paper, 87 FTM 6, Oct. 1987.

[23] R. E. Smith, "Solving Gear Noise Prob With Single Flank Inspection," Power Transmission Design, pp. 63-67, 1990.

[24] “ANSI/AGMA 2009-B1:2001 Bevel gear classification, Tolerances and measuring methods.” 2001.

[25] C. G. Olson, “Gear Testing Machine,” U.S. Patent 1554 646, Sept. 22, 1925.

[26] Mr. Patterson, Mr. Timms, Capt. Stewart, Mr. Orcutt, Mr. Yoxen, Mr. Walker, Mr. Sykes, Mr. Parkinson, Mr. MacArthur, and Dr. Darlington, "Discussion on 'Gear measurement and allied subjects' at the British Gear Manufacturers’ Association,” Prod. Eng. Journal, Inst., vol. 34, no. 12, pp. 801-804, 1955.

[27] C. W. Mahr, "Electrically Operated Testing Apparatus for Gears and Similar Toothed Elements," U.S. Patent 2687 576, August 31, 1954.

[28] K. Müller, "Rolling Gear Tester,” U.S. Patent 3031 765, May 1, 1962.

[29] K. Müller, "Testing Apparatus for Total Single-Flank Composite Errors in Cylindrical Gears," U.S. Patent 3583 072, June 8, 1971.

[30] H. Spaeth, "Double-Flank Composite Error Tester," U.S. Patent 4550 508, Nov. 5, 1985.

[31] S. Matsumoto, “Double Flank Meshing Test Method,” U.S. Patent 5689 993, Nov. 25, 1997.

[32] H. Bertz and P. Golder, "Double Flank Rolling Tester," U.S. Patent 6766684 B2, July 27, 2004.

[33] Y. C. Chen and C. C. Lo, "Method for Determining the Precision of Gears," Patent US 2014/0088891 A1, March 27, 2014.

[34] R. G. Munro, "Feedback from the Field," Gear Technol., vol. 23, no. 5, p. 9, 2004.

[35] J. D. Smith and D. B. Welbourn, "Gearing Research in Cambridge 1827-2000.” [Online]. Available: http://www-g.eng.cam.ac.uk/125/achievements/gears/. [Accessed: 11-Nov-2016].

[36] E. Guenter, "Single Flank Total Composite Error Test. Most Ingenious Method of Tooth Quality Control," Werkstatt und Betrieb, vol. 102, no. 5, pp. 283-288, 1969.

[37] Anon, "Design Evaluation of the Goulder-Mikron Single Flank Gear Tester," EM\&D Eng. Mater. Des. , vol. 16, no. 3, pp. 31-35, Nov. 1972.

[38] A. Ishibashi, S. Tanaka, and T. Ueno, "Super-Precision Single-Flank Gear Testing Machine," Am. Soc. Mech. Eng., Tech. Paper, no. 77 -DET-118, Jan. 1977.

[39] R. G. Munro, "Review of the Single Flank Method for Testing Gears," Ann. ICRP, vol. 28, no. 1, pp. 325-329, 1979.

[40] W. D. Mark, "The Transfer Function Method for Gear System Dynamics Applied to Conventional and Minimum Excitation Gearing Designs," NASA Contract. Rep. 3626, pp. 2-3, 1982.

[41] R. E. Smith, "What Is Runout, and Why Should I Worry About It?" Gear Technol., vol. 8, no. 1, pp. $43-$ 44, 1991.

[42] R. E. Smith, I. Laskin and D. Bailey "Detection of Hidden Runout," AGMA, Tech Paper, 95 FTM 1, Oct. 1995. 
[43] Z. Zhang, T. Huang, S. Huang, D. Kang, W. Hong, R. Duan, and L. Xu, "A new kind of gear measurement technique,” Meas. Sci. Technol., vol. 8, no. 7, pp. 715-720, Jul. 1997.

[44] "Frenco - Inspecting all flanks in minutes," Gear Technol., vol. 21, no. 3, pp. 9-11, 2004.

[45] R. L. Thoen, “Calibration of Two-Flank Roll Testers," Gear Technol., vol. 25, no. 3, pp. 58-60, 2008.

[46] L. Guo, K. Chen, and X. Zhai, "Error separation technique for double flank gear testing," in 7th Int. Symp. Instr. Control Tech.: Meas. Theory Syst. Aeron. Equip., 2008, vol. 7128, p. 71280N-71280N-6.

[47] L. Cao, "The measuring accuracy of the multistep method in the error separation technique," J. Phys. E., vol. 22, no. 11, pp. 903-906, Nov. 1989.

[48] S. Tong, "Two-step method without harmonics suppression in error separation," Meas. Sci. Technol., vol. 7, no. 11, pp. 1563-1568, 1996.

[49] J. Chajda, M. Grzelka, and Ł. Mądry, "Dynamic Deviation Error In Single Flank Gear Testing," XIX IMEKO World Congr., pp. 1857-1862, 2009.

[50] C.-C. Liu and K.-H. Lin, "Simulation of double flank gear rolling testing," in ASME 2009 Inter. Design Eng. Tech. Conf. and Comp. Inf. Eng. Conf., IDETC/CIE2009, 2009, vol. 6, pp. 255-262.

[51] F. L. Litvin, Development of Gear Technology and Theory of Gearing, NASA Ref. Publ. 1406, vol. ARL-TR-150. 1997.

[52] F. L. Litvin and A. Fuentes, Gear Geometry and Applied Theory, Second Edition, Cambridge University Press, 2004.

[53] R. E. Smith, “Quality gear inspection. Part I,” Gear Technol., vol. 11, no. 5, pp. 32-38, 1994.

[54] M. Yong, W. Tongxiang, L. Zhifeng, W. Liding, and Z. Yuling, "Measuring instrument for radial composite deviations of high-precision master gear,” in 6th Int. Symp. Prec. Eng. Meas. Instr., 2010, vol. 7544 , p. $75445 \mathrm{~N}-75445 \mathrm{~N}-7$.

[55] X. Huakun, F. Ying, F. Gang, Y. Yong, and H. Wenliang, "New Way For Accuracy Measurement Of Fine-Pitch Gears In Batch Production," in 4th International Seminar on Modern Cutting and Measurement Engineering, 2010, vol. 7997, p. 79971A-79971A-6.

[56] M. Cui and W. Y. Deng, "Application of Error Separation Technique on the Virtual Detector of Gear Error,” Adv. Mater. Res., vol. 538-541, pp. 3038-3042, Jun. 2012.

[57] M. Pueo, J. Santolaria, R. Acero, and G. Aso, "Double Flank Roll Testing Machines Intercomparison for Worm and Worm Gear,” Procedia Eng., vol. 63, pp. 454-462, 2013.

[58] E. Reiter and F. Eberle, "Practical Considerations for the Use of Double-Flank Testing for the Manufacturing Control of Gearing - Part I,” Gear Technol., vol. 31, no. February, pp. 44-51, 2014.

[59] E. Reiter and F. Eberle, "Practical Considerations for the Use of Double-Flank Testing for the Manufacturing Control of Gearing - Part II,” Gear Technol., vol. 31, no. April, pp. 60-69, 2014.

[60] Z. Shi and J. Tang, "Research On A Measurement Principle Of The Double-Flank Gear Rolling Test With Many Degrees Of Freedom For Fast Inspection," in 7th International Symposium on Instrumentation and Control Technology: Sensors and Instruments, Computer Simulation, and Artificial Intelligence, 2008, vol. 7127, p. 71271C-71271C-6.

[61] Z. Shi, J. Tang, H. Wei, Y. Gao, and C. Liu, "Gear in-line measuring machine based on double-flank gear rolling test with multi-degrees of freedom,” Chinese J. Sci. Instr., vol. 30, no. 2, pp. 303-307, 2009.

[62] J. Tang and Z. Shi, "Repeatability test of in-line gear measuring machine," in 7th Int. Symp. Prec. Eng. Meas. Instrum., 2011, vol. 8321, p. 832115.

[63] Z. Shi and X. Zhang, "Development and application of gear single-flank testing technology," Tool Eng., vol. 42, no. 3, pp. 10-15, 2008. 
[64] Y. Kang, Z. Shi, and J. Lin, "The Gear Pair Integration Error Curve and Its Atlas," in Proc. Soc. PhotoOpt. Instr. Eng. (SPIE), 2008, vol. 7128, p. 71281V-71281V-8.

[65] Z. Shi, W. Zhang, and H. Qu, "Development of measuring machine based on single-flank testing for finepitch gears,” Yi Qi Yi Biao Xue Bao/Chinese J. Sci. Instrum., vol. 32, no. 4, pp. 913-919, 2011.

[66] Z. Shi, H.-F. Qu, and W.-N. Zhang, "Design Of Single-Flank Rolling Tester for Fine-Pitch Gears," J. Beijing Univ. Technol., vol. 37, no. 4, pp. 481-486, 2011.

[67] J. Tang, Z. Shi, and Z. Q. Fang, "Novel measuring principle of pitch deviation evaluated through doubleflank gear rolling test with rack probe," in Key Engineering Materials, 2012, vol. 523-524, pp. 832-835.

[68] J. Tang, Z. Shi, and Z. Fang, "Novel measurement principle of profile deviations evaluated through double-flank rolling test with rack probe," in 8th Int. Symp. Prec. Eng. Meas. Instrum., 2013, vol. 8759, p. $87591 P$.

[69] Z. Shi, X. Lu, C. Chen, and J. Lin, "Development of transmission error tester for face gears," in Proc. SPIE 8916, Sixth Int. Sympo. Prec. Mech. Meas., 2013, vol. - 8916, no. -, p. 891605.

[70] A. Albers, N. Burkardt, T. Deigendesch, C. Ellmer, and S. Hauser, "Validation of micromechanical systems," Microsyst. Technol., vol. 14, no. 9-11, pp. 1481-1485, Mar. 2008.

[71] A. Albers, T. Deigendesch, H.-G. Enkler, S. Hauser, P. Leslabay, and J. Oerding, "An integrated approach for validating micro mechanical systems based on simulation and test," Microsyst. Technol., vol. 14, no. 12, pp. 1781-1787, May 2008.

[72] A. Albers, P. Börsting, T. Deigendesch, H.-G. Enkler, and P. Leslabay, "Micro gear validation: improving the correlation between virtual and physical testing," Microsyst. Technol., vol. 16, no. 8-9, pp. 1529-1535, Jan. 2010.

[73] F. Du, J. Lu, X. Zhao, H. Yang, and W. Li, "Research on virtual single-flank-meshing measurement of micro spur gear," in 2010 Int. Conf. Comp. Appl. Syst. Mod. (ICCASM 2010), 2010, vol. 13, pp. V1348-V13-51.

[74] Y.-C. Liu, N.-C. An, S.-H. Yang, S.-Z. Yan, and S.-L. Chen, "The study of double flank micro gear roll testing," in 7th Int. Symp. Prec. Eng. Meas. Instrum., 2011, vol. 8321, p. 83212B.

[75] R. Acero, J. Santolaria, and M. Pueo, "Verification Methods for Micro Gears. Analysis of Double Flank Roll Testing Applied to Micro Gears," Procedia Eng., vol. 63, pp. 142-150, 2013.

[76] D. P. Townsend, "Gear Tolerances," in Dudley’s Gear Handbook, 1st ed., McGraw-Hill, 1991, pp. 7.17.45 .

[77] “www.iso.org." [Online]. Available:

http://www.iso.org/iso/home/standards_development/list_of_iso_technical_committees/iso_technical_co mmittee.htm?commid=49212. [Accessed: 11-Nov-2016].

[78] “ANSI/AGMA 2015-1-A01 Accuracy Classifications System - Tangential Measurements for Cylindrical Gears." 2001.

[79] "ISO/TR 10064-1:1992 Cylindrical gears - Code of inspection practice - Part 1: Inspections of corresponding flanks of gear teeth.” 1992.

[80] "ISO/TR 10064-2:1996 Cylindrical gears - Code of inspection practice - Part 2: Inspections related to radial composite deviations, runout, tooth thickness and backlash.” 1996.

[81] "ISO 1328-1:1995 Cylindrical gears - ISO system of accuracy - Part 1: Definitions and allowable values of deviations relevant to corresponding flanks of gear teeth." 1995.

[82] “ISO 1328:1975 Parallel involute gears - ISO system of accuracy." 1975.

[83] "ISO 21771:2007 Gears - Cylindrical involute gears and gear pairs - Concepts and geometry." 2007.

[84] "DIN 3960:1987 Definitions, parameters and equations for involute cylindrical gears and gear pairs." 1987. 
[85] "DIN ISO 21771:2014 Gears - Cylindrical involute gears and gear pairs - Concepts and geometry.” 2014.

[86] "DIN 21773:2014 Gears - Cylindrical involute gears and gear pairs - Inspection dimensions of tooth thickness." 2014.

[87] “ANSI/AGMA 2000-A88 Gear Classification and Inspection Handbook.” 1988.

[88] E. Lawson, "New ANSI/AGMA accuracy standards for gears," Gear Technol., vol. 21, no. 2, pp. 22-26, 2004.

[89] “ANSI/AGMA 2015-2-A06 Accuracy Classifications System - Radial Measurements for Cylindrical Gears.” 2006.

[90] E. Reiter, "Towards an Improved AGMA Accuracy Classification System on Double-Flank Composite Measurements," Gear Technol., vol. 29, no. June, pp. 52-58, 2012.

[91] “ANSI/AGMA 2116-A05 Evaluation of Double Flank Testers for Radial Composite Measurement of Gears.” 2005.

[92] "AGMA 935-A05 Recommendations Relative to the Evaluation of Radial Composite Gear Double Flank Testers.” 2005.

[93] “RWZ E 10 2014: Double flank gear roll inspection machines.” Frenco, Oct. 2014. 